


\title{
LA CRISIS DE 2007 VISTA DESDE LAS FINANZAS
}

\author{
Autor: Fernando Gómez-Bezares. ${ }^{1}$ \\ Catedrático de Finanzas. \\ Deusto Business School.
}

\section{Resumen}

El primer objetivo de este artículo es resumir el contenido de la teoría financiera, tal como se explica en facultades y escuelas de negocios, con sus virtudes y sus deficiencias, vistas estas últimas, sobre todo, a la luz de la crisis que comenzó en 2007, proponiendo caminos para superarlas. También se hace un análisis más global sobre los orígenes y los caminos para superar la crisis. Y se pone énfasis en los fallos éticos y cómo arreglarlos. La tesis fundamental es que, con lo que hemos aprendido en siete años de crisis, hay bastantes cosas que tenemos que mejorar.

Palabras clave. Crisis de 2007, Teoría Financiera, Valores Éticos, Superación de la Crisis.

The 2007 crisis from a financial perspective.

\footnotetext{
${ }^{1}$ f.gomez-bezares@deusto.es
} 


\begin{abstract}
The first objective of this paper is to summarize the content of financial theory, as it is explained in business schools, their strengths and weaknesses, proposing ways to overcome the latter, specially taking into account the crisis that began in 2007. It also gives a more comprehensive analysis of the origins and the ways to overcome the crisis. And the emphasis is put on ethical failures and how to solve them. The main thesis in that, with what we have learned in seven years of crisis, there are many things that need to be improved.
\end{abstract}

Keywords: 2007 Crisis, Financial Theory, Ethical Values, Overcoming Crisis

Recibido: 13-01-2014

Aceptado:10-03-2014

\title{
1. INTRODUCCIÓN.
}

En las líneas que siguen abordaremos la crisis que comenzó el año 2007, y que seguimos padeciendo, fijándonos principalmente en los aspectos financieros, pero haciéndolo desde una perspectiva ética. Aunque no soy un especialista en ética, sí he leído lo suficiente como para saber que no es fácil encontrar fundamentos universalmente aceptados para las afirmaciones éticas. Si uno se adentra en el pensamiento nazi, puede encontrar una "justificación" para sus brutalidades, y lo mismo ocurre con muchas ideologías extremistas. Sin embargo creo (aunque no lo puedo demostrar) que los seres humanos tendemos a ver como buenas una serie de acciones: ayudar al que lo necesita, decir la verdad, obrar con humildad, alegrarse del éxito del prójimo, ocuparse de la familia, actuar diligentemente, etc.; y otras como malas: pensar solo en uno mismo, matar, robar, maltratar, etc. Para muchos esto tiene un origen trascendente, como cuando decía la Antígona de Sófocles que hay leyes que los dioses han puesto en el corazón de los hombres, para otros será un tema cultural..., pero, en cualquier caso, parece que esos principios son compartidos por gran parte de nuestra sociedad.

Podemos, partiendo de lo anterior, decir que la economía deberá crear riqueza y repartirla; es decir, ser eficiente en la utilización de los recursos y distribuir adecuadamente la renta conseguida. Esta idea nos guiará en las páginas que siguen, donde expondré humildemente mi forma de ver estos temas.

La verdad es que siete años después del inicio de la crisis podemos afirmar que hubo cosas que se hicieron realmente mal antes de 2007; desde entonces se han seguido haciendo cosas muy mal (tal vez algunas menos que antes) y seguimos sin resolver problemas fundamentales: fallan las regulaciones nacionales y supranacionales, tenemos un enorme déficit de valores, la distribución de la renta es muy injusta... Tal vez el 
lector quiera introducir moderación en mi discurso, haciendo sus propios incisos: "son problemas que no se arreglan en un lustro, ni en varios", puede pensar; pero lo grave es que avanzamos muy poco, e incluso, a veces, retrocedemos. Después de lo que ha pasado debemos reflexionar y, cada uno en la medida de nuestras posibilidades, plantear soluciones, aunque sean modestas, y exigir que se avance, al menos en lo más evidente.

En el trabajo nos plantearemos la crisis de una manera general pero centrándonos en lo que propone la Teoría Financiera. Su estructura será la siguiente: comenzaremos resumiendo brevemente los orígenes de la crisis financiera desde el punto de vista ético y económico; haremos después un resumen de cómo se ha ido construyendo el cuerpo doctrinal de las actuales finanzas y en qué consiste hoy, para pasar a ver desde la perspectiva de la Teoría Financiera (el paradigma vigente) qué fallos tiene el modelo en su implementación, comentando, por ejemplo, problemas con la regulación, problemas de agencia, etc. Terminaremos con algunos apuntes sobre por dónde pueden ir las soluciones: valores éticos (incluidas iniciativas altruistas), regulación más efectiva y más global, transparencia, redistribución...

\section{ALGUNOS COMENTARIOS SOBRE LA CRISIS.}

Podríamos comenzar preguntándonos: ¿qué relación tiene la crisis financiera con la crisis de valores que padecemos? Hace algún tiempo escribí un artículo titulado: "Crisis y pecados capitales" (Gómez-Bezares, 2009), donde ponía de manifiesto la relación entre la crisis y la falta de ética: los comportamientos poco éticos han tenido mucho que ver con el origen y desarrollo de la crisis. Terminaba así:

Otros muchos pecados se han cometido en esta crisis, pero este repaso puede darnos una idea de algo que tengo bastante claro: el sistema económico debe favorecer la iniciativa individual, también debe estar regulado, pero no puede funcionar bien si los agentes, al menos una gran parte de ellos, no actúan moralmente. Un individuo puede beneficiarse materialmente obrando mal, pero para mejorar el bienestar colectivo se necesita que la mayoría actúe bien.

Una sociedad que en ocasiones ha alentado el pecado económico, que muchas veces ha optado por admirar en lugar de criticar al pecador, es también culpable de la crisis que padecemos. [...], deberíamos criticar y denunciar los comportamientos poco éticos, por el bien de los afectados, y por el del propio transgresor ${ }^{2}$.

En mi opinión, nuestro mundo occidental ha perdido valores fundamentales, no solo en sus relaciones económicas, y seguramente esa pérdida de valo-

\footnotetext{
2 Gómez-Bezares (2009, p. 4).
} 
res generales ha influido en el olvido de las normas éticas que deberían regir las relaciones económicas. También tengo claro que la falta de ética ha tenido que ver, y mucho, con el origen de la crisis: codicia, mentira, imprudencia, injusticia..., han abundado demasiado. Luego comentaremos algo de esto.

Vamos a centrarnos ahora en los aspectos económicos, y trataré de bosquejar en ese campo mi visión del origen de la crisis. Lo primero que podemos decir es que la crisis de 2007, que es mucho más que una crisis financiera, se venía gestando desde hacía tiempo, en una serie de importantes desequilibrios. Antes de estallar la crisis financiera, había ya latente una crisis de gran envergadura, cuyos componentes más importantes siguen ahí.

Un elemento muy llamativo es la enorme deuda pública y privada en muchos países, cuya generación fue alentada, sin duda, por unos tipos de interés excesivamente bajos, y claros fallos en los sistemas regulatorios y de supervisión. Esto ha dado lugar a la parte más conocida de la crisis: quiebras, rescates bancarios, rescates de Estados... Pero en el origen de la deuda está el déficit; Estados y familias que gastan más de lo que generan. Además, ha ocurrido algo a lo que no estábamos acostumbrados: algunos de estos Estados muy endeudados, de los que además los prestamistas desconfían, se llaman Francia, Reino Unido, Italia, Estados Unidos, España... Aquí hay un tema de fondo, que es la sostenibilidad del Estado del Bienestar: cuánto podremos gastar en el mundo desarrollado en pensiones, en sanidad, en subsidios..., sin afectar gravemente a nuestra competitividad.

En la misma línea tenemos los desequilibrios comerciales, que han sido enormes en algunos países, como en el caso español. Por otro lado, aunque no se produjeran esos desequilibrios, nuestro modelo de desarrollo no es sostenible. No hay energías fósiles suficientes para seguir consumiendo al ritmo actual, menos si se van incorporando nuevos grandes consumidores como China o la India, lo mismo ocurre con muchas materias primas. El deterioro del medio ambiente representa también un problema no resuelto; y por citar un tercer elemento, la evolución demográfica es altamente preocupante: envejecimientos alarmantes en los países desarrollados y altos crecimientos en muchos países pobres. En definitiva, se han ido acumulando importantes desequilibrios, y no se ve que, sin un cambio de rumbo, se vayan a dejar de acumular.

Algunos países pobres de hace unas décadas se han incorporado con fuerza al desarrollo (los BRICs son un ejemplo), y tienen todo el derecho a ello; pero el caso de China, por ejemplo, que se encuentra entre las primeras economías mundiales y que puede alcanzar, en no mucho tiempo, la primera posición, debe hacer que nos replanteemos un modelo eurocéntrico que ha regido el mundo varios siglos, con la incorporación, en el siglo XX, de Estados Unidos 3 .

\footnotetext{
${ }^{3}$ Para ampliar lo anterior puede verse el Boletín de Estudios Económicos (2011).
} 
Hagamos una simplificación de la crisis, algo caricaturizada pero real: imaginemos un país desarrollado que aumenta sus gastos públicos y, así, aumenta el déficit; el Estado se va endeudando en el exterior. Por otro lado importa mucho más de lo que exporta, y pide prestado en los mercados internacionales. Llega un momento en el que los prestamistas empiezan a desconfiar del país (tanto de la solvencia del sector público como del privado), y no le prestan más, por lo que hay que hacer ajustes públicos y privados que aumentan el paro. El país, y todos los que están en parecidas circunstancias, compran menos en el exterior y el problema se extiende.

La crisis que estamos viviendo es una crisis que afecta de manera especial a los países desarrollados. Muchos miembros de este selecto club tienen importantes problemas, mientras que muchos países emergentes van mejorando sus posiciones en el ranking mundial. Todos los años viajo a Latinoamérica por motivos profesionales, a la vez que mantengo relaciones con numerosas universidades de la región; aparte de las cifras hay una sensación psicológica: hace diez años muchos nos miraban con envidia a los europeos en general y a España en particular, ahora la situación ha cambiado en varios lugares.

Si queremos mantener y mejorar nuestro nivel de vida en los países desarrollados, si queremos mantener el Estado del Bienestar como una de las grandes conquistas sociales europeas, solo nos queda un camino: aumentar nuestra competitividad. El problema fundamental que hoy tienen los países desarrollados (aunque no todos) es de falta de competitividad, ese es el gran reto a largo plazo: ser competitivos con unos salarios dignos y unas prestaciones sociales adecuadas. Sabiendo que otros países también quieren desarrollarse y van a competir con sus propias armas: mano de obra más barata, menores costes sociales, y una formación, unas infraestructuras y una tecnología que van mejorando, lo que hace que los países desarrollados tengamos que esforzarnos cada vez más. Aparte de los problemas financieros, esta crisis ha demostrado que los países emergentes representan un reto para los desarrollados; el problema se veía venir, aunque no se tomaba en serio. Yo creo que ya es evidente (importaciones desde esos países, cierre de empresas, deslocalizaciones...), y que lo será mucho más en unos años. Ante esta situación los hay que piden mayores aranceles o cupos para las importaciones desde terceros países; mi opinión es negativa en términos generales pues no es bueno económicamente, pero sobre todo porque no es bueno éticamente: ellos también tienen derecho a desarrollarse; pero tendremos que ver cómo podemos mantener nosotros un suficiente nivel de competitividad para poder seguir participando, con nuestras características, en el mercado mundial.

\section{CIEN AÑOS DE DESARROLLO FINANCIERO.}

Las finanzas como actividad económica han existido desde muy antiguo, bien podemos remontarnos a más de 3.000 años a.C., con los sumerios, para encontrar 
préstamos con interés o, por lo que hoy conocemos, el primer edificio bancario del mundo: el Templo Rojo de Uruk 4 . Esto ocurre porque las finanzas son útiles; pensemos en un mercado financiero: su objetivo es trasladar dinero desde los que ahorran (y, por tanto, les sobra) a los que quieren invertir, o a los que quieren aumentar su consumo en el presente, confiando en su posterior recuperación con los correspondientes intereses. También sirven para trasladar el riesgo desde los que quieren evitarlo a los que aceptan correrlo (cobrando un precio por ello), es lo que hacen, por ejemplo, los mercados de futuros. Estas funciones, aparte de los mercados, las pueden hacer los bancos o las compañías de seguros, dos típicas instituciones financieras. Sin olvidar las finanzas empresariales que se dedican a captar los fondos necesarios para su actividad en las mejores condiciones, para luego invertirlos en dicha actividad con el objetivo de crear riqueza.

Pensemos en los mercados de derivados (instrumentos financieros vilipendiados antes de la crisis, pero mucho más después de 2007), y centrémonos en los "futuros" que permiten vender en el futuro un bien a un precio pactado hoy; la existencia de este tipo de contrato puede ser muy interesante. En efecto, pensemos en un viticultor riojano muy preocupado por la evolución futura de los precios de la uva que decide vender su cosecha a futuros, trasladando así el riesgo al comprador; alguien puede pensar que esto no hace más que llevar el riesgo de un agente a otro, pero no es solo eso, el interés económico de tal operación consiste en que el agricultor puede trasladar el riesgo a alguien más grande (al que le afecta menos el riesgo) y/o a alguien que lo puede diversificar mejor, por lo que cobrará por correr el riesgo menos de lo que estaría dispuesto a pagar el agricultor, y habrá un beneficio común.

De todo lo anterior el lector puede deducir el interés de las finanzas para el desarrollo económico en su vertiente de mercados, empresas financieras y finanzas empresariales, jugando con dos elementos esenciales: el valor del dinero en el tiempo (si pedimos prestado nos cobrarán un interés) y el riesgo (el que corre riesgos pretende cobrar por ello). Precisamente el control, la medición y la remuneración del riesgo son temas esenciales en las modernas finanzas, en los que se ha avanzado mucho en los últimos sesenta años, como luego comentaremos. Sin embargo podemos recoger la opinión de Pérez Ramírez (2011, pp.21-22): "Un agricultor de la Italia medieval encontraría serias dificultades para adaptarse a las tareas agrícolas tal y como éstas se desarrollan en la Europa del siglo XXI. Frente a ello, Lorenzo de Medici, el mecenas y banquero más famoso de todo el Renacimiento, no emplearía más allá de unos pocos días en comprender y asumir la dirección de cualquiera de los megabancos con que se ha saldado la crisis de las hipotecas subprime en Estados Unidos". Sin duda algo de cierto hay en esto, pues los problemas financieros básicos, valor del dinero en el tiempo y gestión del riesgo, vienen por lo menos desde los sumerios.

\footnotetext{
${ }^{4}$ Véase Pérez Ramírez (2011, p. 31).
} 
También vienen de lejos los escándalos financieros o las burbujas, de los que tenemos interesantes precedentes en la tulipanmanía holandesa de principios del XVII o en la burbuja de los Mares del Sur de la Inglaterra del XVIII ${ }^{5}$, cuando Isaac Newton, tras enormes pérdidas, afirmó: "puedo predecir el movimiento de los cuerpos celestes, pero no la locura de las gentes".

Con todo, el desarrollo de la Teoría Financiera, tal como hoy la conocemos, viene desde hace poco más de cien años. Fue a caballo entre los siglos XIX y XX cuando la creación de grandes empresas, la emisión de títulos en los mercados, el interés por la banca... despertó la necesidad de construir una disciplina que se ocupara de estos temas. Esto ocurría en Estados Unidos, pero bien lo podríamos asimilar (a su debida dimensión) con el desarrollo del Bilbao de principios del siglo XX, donde parecidas consideraciones llevaron a la creación de la Universidad Comercial de Deusto en 1916․ Aparece así el que se ha denominado enfoque tradicional de las finanzas basado en la descripción de las instituciones y los instrumentos, y asociado a autores como A.S. Dewing y C.W. Gerstenberg. A mediados del siglo XX empieza a abrirse paso el enfoque moderno de las finanzas de la mano de autores como H. Markowitz, J. Tobin, F. Modigliani, M.H. Miller, W.F. Sharpe, E.F. Fama, M.C. Jensen, F. Black, M. Scholes, R.C. Merton, R. Roll, S.A. Ross, etc., que tratan temas como la medición y gestión del riesgo en las inversiones, las políticas de financiación y dividendos, el funcionamiento de los mercados, la valoración de diferentes activos, los problemas de agencia... Para la segunda mitad de los años setenta del siglo XX tenemos un cuerpo doctrinal sólido y un interesante número de aplicaciones y contrastaciones. Desde entonces una cantidad creciente de medios humanos, materiales y tecnológicos se ha puesto a disposición de los investigadores, que han desarrollado nuevos modelos y muchísimas más aplicaciones y contrastaciones, pero los elementos básicos del paradigma, denominado paradigma de los setenta, permanecen estables ${ }^{8}$.

Este es el cuerpo teórico que poseen las actuales finanzas y que está recogido en los principales manuales que se manejan en las facultades y escuelas de negocios de todo el mundo. Trataremos de resumir las ideas fundamentales: el objetivo financiero de la empresa es maximizar su valor en el mercado, lo que se consigue fundamentalmente con unas correctas políticas de inversión; ese valor queda reflejado adecuadamente por unos mercados de capitales eficientes y se calcula con los correspondientes modelos de valora-

\footnotetext{
${ }^{5}$ Pueden verse Malkiel (1992) o Galbraith (1991).

${ }^{6}$ Amat (2008, p.20).

${ }^{7}$ Véase Revuelta (1992).

${ }^{8}$ Todo esto puede ampliarse en Gómez-Bezares (1995 y 2005), donde también pueden encontrarse algunas obras representativas de los autores arriba citados.
} 
ción (el más típico es el CAPM). Y todo esto se fundamenta en un método de investigación caracterizado por la construcción de modelos y su posterior contrastación empírica. Estas ideas quedan reflejadas en la Figura 1.

\section{Figura 1. El Paradigma de los Setenta}

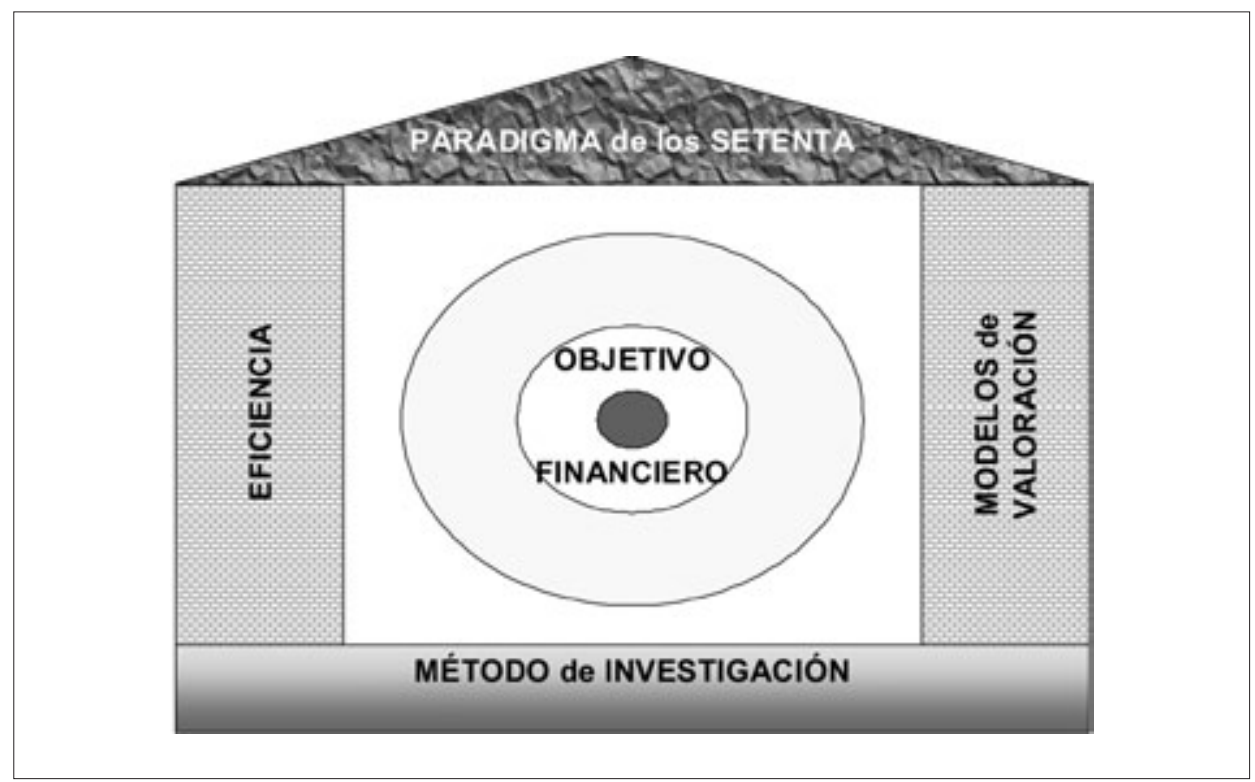

Fuente: Gómez-Bezares (2010, p. 57).

Ciertamente el paradigma ha sufrido importantes críticas que ponen en duda la eficiencia de los mercados y la utilidad de los modelos de valoración, quizá la más fuerte venga desde las finanzas conductuales que discuten la forma de racionalidad que las finanzas han venido atribuyendo a los agentes financieros (véase Figura 2), pero tampoco está exento de discusión el propio objetivo financiero o el método de investigación. Con todo, las finanzas que se explican en facultades y escuelas de negocios siguen el paradigma descrito. En él deben incluirse los problemas de agencia: las decisiones en las grandes compañías las toman los directivos, cuyos intereses no siempre están alineados con los de los accionistas $y$, en consecuencia, con el objetivo financiero. Para conseguir el alineamiento se proponen sistemas de incentivos y procedimientos de $\operatorname{control}^{9}$ que han inspirado, en buena parte, el Gobierno Corporativo ${ }^{10}$.

\footnotetext{
${ }^{9}$ Jensen y Meckling (1976).

${ }^{10}$ Para el caso español puede verse Sánchez Marin (2011).
} 
Figura 2. Ataques al Paradigma de los Setenta

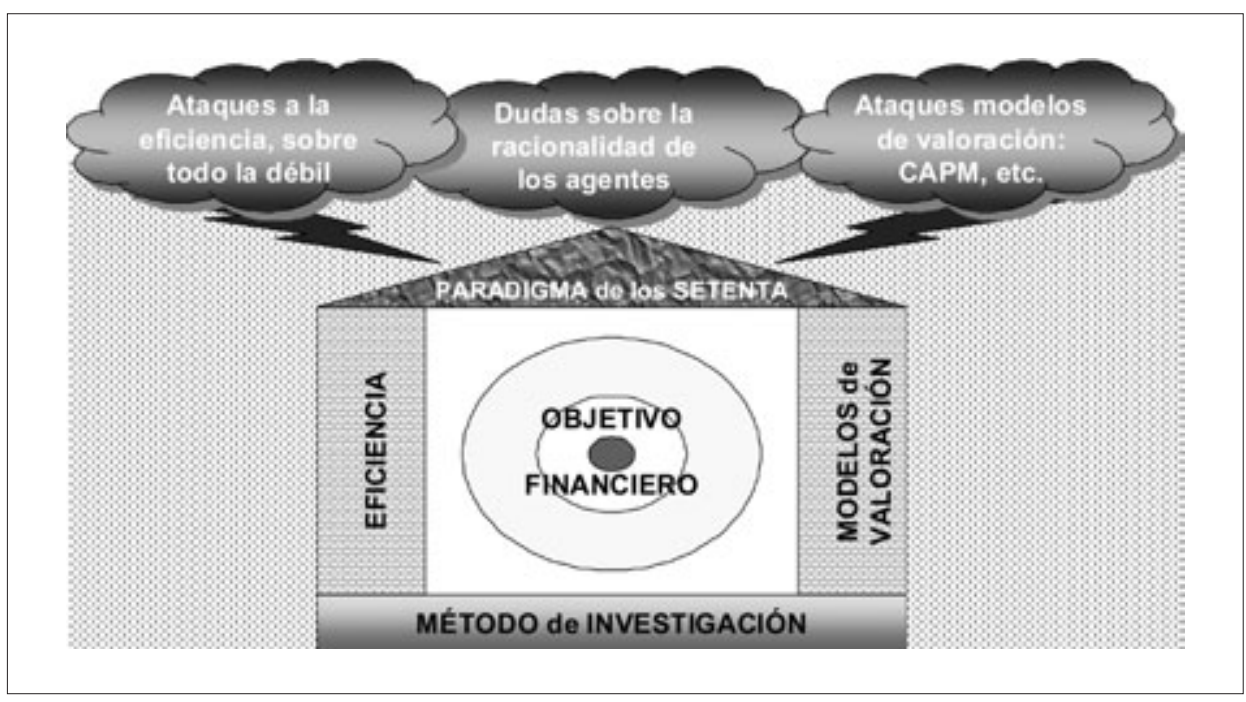

Fuente: Gómez-Bezares (2010, p. 58).

En mi opinión los problemas de agencia han sido unos de los causantes próximos de la crisis que padecemos. Muchos directivos, amparados por una cultura anglosajona y unas prácticas que sobrevaloran los resultados a corto plazo, han puesto sus intereses (económicos, de poder) por encima de los de la empresa en general y de los accionistas en particular, lo que pone en duda todos los avances que se habían hecho en Gobierno Corporativo. Cuando en finanzas se habla de maximizar el valor de la empresa, nos referimos (o al menos a eso me refiero yo) a maximizarlo con una perspectiva de largo plazo, y eso es incompatible con la asunción de riesgos excesivos que han practicado, por ejemplo, muchas entidades financieras. Lo que ocurre es que, al no haber funcionado adecuadamente los sistemas de información y los encargados de valorar los riesgos (como las agencias de rating), muchas de estas entidades iban dando buenos resultados lo que permitía a los directivos interesantes recompensas. Luego, con la crisis, ha venido el desastre para bastantes de ellas, y los problemas para la mayoría; pero los directivos no solo se llevaron el dinero en su día, sino que incluso siguen cobrando cantidades injustificables.

También es interesante la línea de investigación de Ley y Finanzas que nace a caballo entre los siglos XX y XXI ${ }^{11}$. El problema es que defiende el modelo anglosajón de hacer finanzas, que sin duda tiene muchas virtudes, pero la crisis de 2007 debe hacernos pensar que también deberemos cambiar algunas cosas.

\footnotetext{
${ }^{11}$ Véase Gómez-Bezares (2010).
} 
En resumen, las finanzas en nuestros días tienen un cuerpo de doctrina bien construido, que es consciente de uno de sus grandes retos: resolver o al menos mitigar el problema de agencia, y cuyos críticos tratan de avanzar por el conductualismo. También ha existido cierta autocomplacencia al mirar el modelo anglosajón (donde se ha desarrollado la Teoría Financiera en los últimos cien años), que es en el que todos los países se han ido inspirando, de una u otra forma.

Quizá sea interesante para el lector el resumen de los temas que se estudian en las finanzas actuales, tal como se refleja en la Figura 3.

Figura 3. Las Finanzas en nuestros días

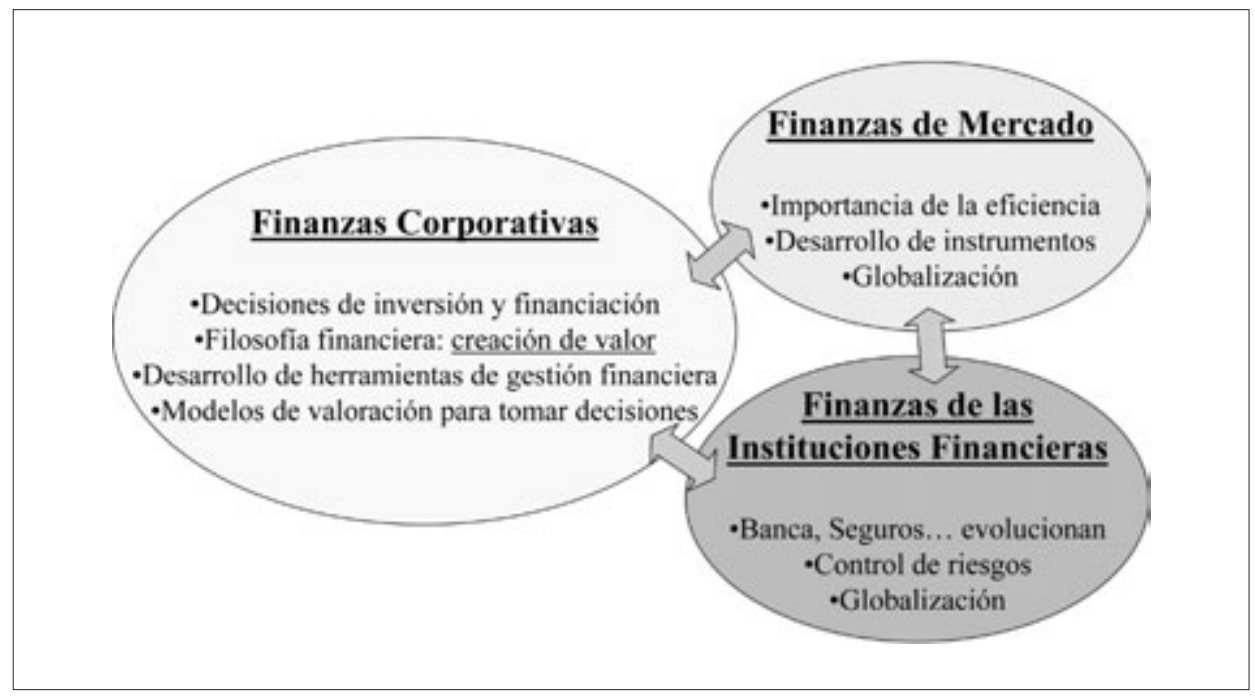

Fuente: elaboración propia.

\section{AlguNOS FAlloS DEL MODELO EN LA PRÁCTICA.}

Veremos brevemente en las siguientes líneas algunos de los problemas del actual modelo financiero que se han puesto de manifiesto en la crisis de 2007. Partimos de la siguiente idea: dentro de una adecuada regulación y una correcta forma de proceder, las empresas que maximizan su valor (objetivo financiero) lo consiguen porque ofrecen buenos productos a sus clientes a un precio adecuado, y eso se logra asignando correctamente los recursos puestos a su disposición; es decir, realizan una labor social que se traduce en un incremento de riqueza. Las empresas compiten entre sí para quedarse con los clientes, y serán las más competitivas, las mejores, las que tengan éxito. 
Hasta aquí el modelo parece bastante lógico, pero enseguida aparecen los problemas. El primero ya lo hemos comentado más arriba: al ser los directivos los que toman las decisiones en las grandes empresas, no está claro que vayan a tratar de maximizar el valor de la empresa (lo que lleva a la correcta asignación de los recursos), y pueden inclinarse por aumentar sus ingresos (llegándose a remuneraciones y privilegios escandalosos, tal como se ha denunciado durante la crisis) o a aumentar su poder (mediante un crecimiento de la empresa no necesariamente interesante desde el punto de vista de la eficiencia). La crisis ha puesto al descubierto muchas "malas prácticas" de los directivos, desde falsear la información hasta asumir riesgos excesivos para mejorar los resultados a corto plazo o aumentar su tamaño.

Los fallos en el control de riesgos han sido uno de los temas estrella en esta crisis. Desde mediados del siglo XX se ha trabajado mucho en el tratamiento del riesgo. Se han desarrollado potentes modelos econométricos para medir los riesgos, que, al parecer, en distintas ocasiones, no han funcionado. El primer problema es que muchos de los usuarios no conocen bien estos modelos, y al final son más útiles las reglas sencillas. Por otro lado se ha pecado de optimismo, pensando que una gran crisis nunca iba a llegar. Lo que es claro es que el control de riesgos ha fallado de forma patente en muchas entidades financieras, por lo que ahora se les insta a aumentar sus fondos propios.

Otro problema del modelo es que lleva a una mala distribución de la renta. Los más valiosos, o los que tienen mejores ideas, o aquellos que tienen más suerte, pueden llegar a acumular mucha riqueza, en detrimento de los más desfavorecidos. La economía se mueve por el incentivo económico, y eso, dentro de unos determinados límites, creo que es positivo; pero la realidad es que las desigualdades son excesivas dentro de nuestra sociedad. Los financieros, tradicionalmente, al llegar a este punto hemos pasado la responsabilidad al Estado: que sea la "Política" la que se encargue de la redistribución. Yo participo de esta idea, pero también una sana Responsabilidad Social Corporativa puede ayudar en esta línea.

Decíamos más arriba que el modelo precisa de una adecuada regulación. Yo creo que este punto es fundamental. Debe haber una correcta regulación (huyendo de la regulación excesiva) y una diligente supervisión (que tampoco sea agobiante); y la regulación financiera ha fallado, tal como hemos visto en España o en Estados Unidos. Por un lado la "ingeniería financiera" ha dado lugar a productos muy complejos, mientras que productos relativamente sencillos, pero con un claro riesgo, se han colocado masivamente. Suele ocurrir que en épocas de euforia se vende casi cualquier producto financiero, siempre que prometa buenas rentabilidades. No ha habido una suficiente comprensión del riesgo asumido, ni por los particulares ni por los profesionales. Sin duda la competencia entre plazas financieras y los paraísos fiscales han influido en la actitud permisiva de muchos reguladores. La idea de que los mercados se autorregulan ciertamente no ha funcionado, siendo especialmente patentes los errores de las agencias de rating. 
Probablemente reguladores y supervisores tendrían un trabajo más fácil si las empresas fueran más transparentes. La transparencia permite a los mercados hacer mejor su labor de control, y el supervisor puede hacer mejor su trabajo si no tratan de engañarle. Pero a pesar de muchas declaraciones grandilocuentes de transparencia, la crisis ha puesto de manifiesto los enormes déficits que tenemos en este campo.

Pensemos un momento en el tema de la especulación. En un mercado financiero, como en otros mercados, los especuladores, si actúan en igualdad de condiciones, son útiles. Ellos tratan de adivinar la evolución futura de las cotizaciones, comprando lo que creen barato y viceversa, lo que es útil pues mejora la eficiencia (los mercados van a valorar mejor, al empujar los especuladores los precios hacia su verdadero valor) y la liquidez. Pero si lo que hacen es manipular las cotizaciones presionándolas hacia arriba para vender (y al revés), ganarían dinero actuando contra la ética y falsearían la cotización. Si utilizan información privilegiada se estarían enriqueciendo inmoralmente y, además, los inversores corrientes, al saber que esto ocurre, aumentarían su desconfianza sobre los mercados. Estas prácticas se engloban en lo que se denomina "abuso de mercado" y están prohibidas y perseguidas por los organismos correspondientes. El problema es que no es fácil detectarlas ni probarlas. Vemos aquí un caso donde el incentivo económico lleva a ciertos agentes a actuar en contra del interés común, y donde las autoridades lo tienen complicado. Sin duda se podrá mejorar la regulación, la supervisión y el sistema de sanción, pero es fundamental inculcar en los agentes valores éticos: está bien ganar dinero dentro de las reglas, pero no puede hacerse fuera de ellas. Deberíamos avergonzarnos de ello.

Creo que esto último es la clave: los agentes financieros (como los demás seres humanos) deben cultivar unos valores éticos. Hay cosas que, simplemente, no se pueden hacer, y otras que hay que hacer. Una mayor transparencia ayudará a un mejor comportamiento, una buena regulación y supervisión también, pero al final, en un mundo tan complejo, tendrá que ser la conciencia individual la que nos ponga ciertos límites o nos fuerce a determinadas actuaciones. Y creo que es también importante la conciencia colectiva, sobre todo la del conjunto de agentes: si tu entorno ve algo muy mal, te costará más justificarte para hacerlo.

Entran aquí en juego dos ideas que pueden ser interesantes: por un lado nuestros competitivos mercados de directivos pueden estar provocando un fenómeno de "selección adversa" en el terreno moral, pues puede ocurrir que sean los más inmorales los que más fácilmente asciendan, mientras personas con sólidos valores morales, por negarse a hacer determinadas cosas, quedan estancadas o son expulsadas; la crisis ha puesto de manifiesto que muchos altos directivos actuaron mal, y este fenómeno puede explicar muchas cosas. Otro tema importante es la educación en valores de los futuros directivos, lo que permitiría luchar contra el fenómeno antes citado, como veremos más adelante. 


\section{RUPTURA O REFORMA.}

La crisis ha puesto de manifiesto importantes disfunciones del modelo: falsedades, escándalos, grandes quiebras, necesidad de dinero público para solventar problemas de empresas privadas, empobrecimiento general a causa de malas actuaciones, mal reparto de las cargas de la crisis... Estas cosas ya ocurrían antes de la crisis, pero en los últimos años estos episodios se han multiplicado. Ante esta situación algunos piden un cambio de modelo, otros una reforma en profundidad; incluso los hay que no quieren cambiar nada. Pienso que, ante la gravedad de la crisis que estamos padeciendo, esto último no es defendible, aunque algunos notables profesores de Chicago estén en esa línea (véase Cassidy, 2010). Respecto a las dos primeras posibilidades mi postura personal es favorable a la reforma, y esto por dos razones: en primer lugar, desde la caída del muro de Berlín en 1989, carecemos de un modelo alternativo al de mercado: las economías planificadas centralmente fracasaron, y modelos mixtos, como el Chino, no parecen exportables a Occidente. Por otro lado es muy peligroso hacer experimentos con modelos no contrastados.

Las personas de mi generación vivimos con apasionamiento juvenil la transición hacia la democracia. Recordemos cómo en la España predemocrática de mitad de los años setenta se discutió mucho sobre si era bueno hacer una reforma desde el régimen franquista o proceder a la ruptura. En aquella ocasión se optó por la reforma y la transición española fue vista como un éxito en muchos lugares. La Iglesia Católica, la entidad más antigua del mundo, ha sufrido importantes crisis a lo largo de su historia, y ha tenido importantes reformas, pero ha mantenido su continuidad. Lo mismo ha sucedido con instituciones básicas como la familia o sistemas como la democracia, han ido cambiando con el tiempo, se han ido reformando. Podríamos buscar otros muchos ejemplos que nos hablan de las posibilidades de los procesos de reforma a lo largo de la historia.

No es posible hacer aquí un plan completo para reformar nuestro sistema de mercado, pero sí quiero dar algunas ideas. Lo primero creo que son los valores. En un sistema basado en la libertad individual, si los agentes económicos, al menos en su mayoría, no actúan éticamente, las cosas no pueden funcionar bien. En este sentido me parece fundamental que la sociedad asuma como suyos unos valores comunes, y los inculque en sus miembros. Es importante que el que actúa mal sea censurado (antes que castigado) por su entorno, y que el que actúa bien sea admirado. Con demasiada frecuencia hemos actuado al revés, calificando como "vivo" al que se escaquea y como "tonto" al que trabaja honestamente. En esta tarea de concienciación colectiva todos somos importantes, pero tal vez debamos destacar a los políticos, a los periodistas, a los profesores, a las organizaciones religiosas... Tenemos que denunciar lo que está mal y aplaudir lo que está bien. El ser humano responde a los incentivos y la opinión de nuestros conciudadanos sobre nosotros puede ser un incentivo importante. 
En ese compartir unos valores comunes, es fundamental inculcarlos al conjunto de la población. La sociedad transmite esos valores mediante diferentes mecanismos, pero sin duda, uno esencial es la educación, que ayuda a que tanto individual como colectivamente se asuman como propios unos determinados valores morales. Las facultades y escuelas de negocios tienen aquí un papel fundamental inculcando en los futuros directivos esos valores. Si lo hacemos bien y el conjunto de directivos los asume como propios, la presión del conjunto ayudará a minimizar los comportamientos inmorales.

Por otro lado hemos de ser conscientes de una realidad de nuestro siglo: la globalización, y eso debe hacernos cambiar algunas cosas. Si aplicamos las funciones que Adam Smith atribuía al soberano a un mundo global, necesitaremos grandes pactos supranacionales para evitar todo tipo de confrontación militar entre Estados, o dentro de los propios Estados, también deben reforzarse las atribuciones de los tribunales internacionales para evitar la injusticia, o deben realizarse grandes actuaciones globales que benefician a la colectividad como el cuidado del ecosistema. Estas actividades, hoy en día, sobrepasan las posibilidades de los Estados, o incluso de entes superiores como la Unión Europea (UE), y deben regirse por acuerdos e instituciones que engloben a toda la humanidad. Pero además de lo anterior $^{12}$ es necesario que se establezcan regulaciones a nivel global; de poco sirve una regulación financiera muy estricta en un país, si las entidades se domicilian en paraísos regulatorios, o una determinada política fiscal progresiva, si los contribuyentes con más dinero "huyen" hacia países "más comprensivos". Todo esto no se puede hacer de la noche a la mañana, pero se puede ir un poco más rápido de lo que se va. Primero unificando a nivel de la UE, y luego, al menos en lo fundamental, a nivel global. El problema es, por un lado, que para hacer esto hay que luchar contra intereses muy fuertes, de aquellos que se están beneficiando de la actual situación; por otro lado a los Estados les cuesta mucho perder soberanía. Sin olvidar que será un proceso y un resultado muy complejo.

Pensemos en un entorno cercano y recordemos las dificultades que han aparecido para lograr una armonización fiscal entre los tres territorios vascos, o las peleas que estos temas han suscitado con otras autonomías o con el Estado central; no es difícil comprender que más complicado será poner de acuerdo a los diferentes Estados, con tradiciones jurídicas, culturales..., muy dispares. Pero la armonización es necesaria, si no la legislación será ineficaz. Recordemos el aumento de tributación que se produjo para las SICAVs vascas en 2009, y la salida masiva de este tipo de sociedades que se produjo en 2010. Tendremos que hacer un esfuerzo en armonizar regulaciones, fiscalidad..., pues en un mundo global los agentes hacen arbitrajes trasladándose a donde más les conviene; esto es más patente cuando el traslado es relativamente fácil, al no necesitar grandes inver-

\footnotetext{
${ }^{12}$ Aceptemos o no su inclusión en los famosos "tres deberes del soberano" de Adam Smith.
} 
siones en inmovilizado o importantes infraestructuras, como pasa en las instituciones financieras, pudiéndonos servir como ejemplo el caso de las SICAVs antes comentado.

Pero tengamos claro que una regulación común impondrá serias limitaciones a la capacidad legislativa de los Estados: ya no podrán aprobar las leyes que consideren más convenientes, y también tendrán menos margen las diputaciones forales. En definitiva se trata de un traslado de soberanía, que yo creo que hay que hacer a nivel europeo, primero, y mundial después. Pero no será nada fácil.

También me parece fundamental mejorar la distribución de la renta a nivel global. A lo largo del siglo XX el desarrollo del Estado del Bienestar ha conseguido, en nuestro entorno europeo, una mayor igualdad de oportunidades en educación, y una mejor cobertura en sanidad y otras prestaciones sociales; y, aunque es cierto que en muchos lugares las diferencias de renta han aumentado en los últimos años, yo creo que el balance es positivo. El reto para el siglo XXI es conseguir algo parecido a nivel global, y eso solo se conseguirá con un gran pacto para transferir renta desde los países más ricos a los más pobres. Esa transferencia debería destinarse a mejorar la formación en esos países, las infraestructuras, la sanidad...; apoyarlos con inversiones para que ellos se desarrollen, a la vez que se les ayuda a conseguir un marco jurídico y organizativo que posibilite el desarrollo allí donde no se tiene. Sin duda hay especialistas en economía del desarrollo que pueden concretar mejor que yo estas ideas, pero fijémonos en tres cosas: podemos ayudarles, pero ellos se tienen que desarrollar; eso supone una transferencia importante de recursos, y, en tercer lugar, al comenzar su desarrollo van a hacer la competencia a sectores de escaso valor añadido en los países ricos, lo que también nos causará problemas. Pero es de justicia que actuemos así.

Seamos conscientes de que mientras no mejoremos la distribución de la renta la asignación que hacen los mercados será muy discutible, y dedicaremos recursos a construir yates de lujo pues hay compradores con capacidad de compra, mientras no hay alimentos ni vacunas para los niños de los países pobres, que no tienen capacidad de compra.

Otro tema importante, como ya hemos comentado, es la transparencia. En un mundo globalizado, hoy por hoy, las empresas multinacionales pueden burlar muchas legislaciones nacionales, pero esto puede ser corregido por los mercados si existe la adecuada transparencia y la suficiente conciencia. Veamos un ejemplo que de hecho ha ocurrido algunas veces: supongamos una multinacional que ante la legislación laboral de su país de origen decide trasladar parte de su producción a países subdesarrollados utilizando allí mano de obra infantil, mucho más barata. Esto puede ser legal, pero si hay la suficiente transparencia sus clientes no se sentirán a gusto con esos productos, se irán a la competencia, y la maniobra dejará de ser interesante para la empresa.

Por otro lado, uno de los grandes problemas en las relaciones financieras, y que también ha tenido mucho que ver con la crisis, es la asimetría informativa. 
La transparencia, la información completa y veraz, es cada vez más importante. Y sin duda para apoyar todo esto puede ayudarnos la ética, por ejemplo la kantiana ${ }^{13}$.

Cuando en 2008 se manifestó la crisis con toda su crudeza muchas entidades financieras tuvieron que ser rescatadas. Aunque algunos, como Eugene Fama (véase Cassidy, 2010) no son partidarios, pienso que hubiera sido peor una caída en cadena de entidades financieras. En España hemos vivido esto más recientemente con el rescate de varias cajas de ahorros. El problema que se plantea en estos casos es que estamos usando dinero público para cubrir intereses privados (como los de los depositantes) y puede parecer injusto que otros colectivos (como los preferentistas) no tengan igual trato. Por otro lado aparece un problema de riesgo moral: si sabemos que el Estado se va a hacer cargo de una entidad financiera cuando tenga problemas, probablemente sus responsables tenderán a ser menos prudentes, y los particulares dejarán su dinero en entidades menos solventes pero que remuneren más; estamos primando a los más imprudentes. Con todo, yo creo que es mejor no dejar caer a las entidades, si bien sus accionistas deben asumir las pérdidas y sus directivos todas sus responsabilidades.

\section{UNA REFLEXIÓN FINAL.}

Yo creo que el sistema de mercado es superior a otros que conocemos, porque es más eficiente en la asignación de los recursos; además respeta la libertad individual, lo que es muy importante. Veo también claro que las finanzas han jugado un papel positivo en el desarrollo económico, a la vez que se han dotado en los últimos cien años de una estructura coherente y elegante. Pero algo ha fallado; yo creo que lo primero ha sido una desmedida avaricia de algunos agentes, mayoritariamente financieros, a la vez que han fallado los sistemas de regulación y supervisión. También han fallado otras cosas, desde el criterio de los agentes: se han equivocado actuando con excesivo optimismo, hasta los sistemas de información o el control de riesgos. En todos estos campos tendremos que actuar si queremos salir de esta crisis y no caer pronto en la siguiente. Pero también seamos conscientes de que hay problemas en la economía mundial que habrá que resolver para volver a un crecimiento equilibrado y sostenible.

En 2007 comienza una crisis financiera (hipotecas subprime) que estalla el 2008 (caída de Lehman Brothers) y sigue produciendo problemas serios (crisis de la deuda soberana, dificultades en la banca...). Todo esto tendremos que resolverlo y tratar de que no vuelva a suceder. Pero hay también problemas de desequilibrios a nivel mundial, y sin resolverlos será muy difícil salir definitivamente de la crisis.

\footnotetext{
${ }^{13}$ Un interesante resumen de la historia de la ética puede verse en Camps (2013).
} 
La competencia es buena, y el objetivo financiero de crear valor, de crear riqueza, es muy positivo. Pero esto no puede hacerse a cualquier precio, hay que hacerlo actuando éticamente. En finanzas se suele hablar de crear valor con una perspectiva de largo plazo; eso parece correcto: si los directivos se hubieran fijado en el largo plazo no hubieran hecho muchas cosas que se hicieron en los años previos a la crisis.

Una posibilidad interesante es la Responsabilidad Social Corporativa (RSC). En finanzas suele utilizarse el denominado objetivo financiero, y se ha discutido si debe plantearse ese objetivo o mejor compatibilizarlo con los objetivos del resto de partícipes sociales interesados en la marcha de la empresa (trabajadores, directivos, clientes, proveedores, sociedad..., los denominados stakeholders). Creo que ambas posturas son compatibles pues si queremos maximizar el valor con una perspectiva de largo plazo, esto solo será posible atendiendo los intereses del conjunto de los partícipes. En esta línea entiendo yo la RSC, que me parece interesante para la empresa desde un punto de vista económico: una empresa socialmente responsable será más valorada si tenemos una perspectiva de largo plazo pues sus partícipes estarán más a gusto ${ }^{14}$; por otro lado, una política de transparencia reforzará esas ventajas. En todo caso siempre deberá haber unos límites éticos: cosas que los agentes económicos no deben hacer, sin entrar a discutir si eso es negativo o no para el valor de la empresa.

El problema que puede aparecer con la RSC es que los directivos la utilicen para limitar el control por parte de los accionistas, aduciendo que son responsables ante el conjunto de partícipes, con una clara propensión a los problemas de agencia. Para ello es necesario reforzar y mejorar los sistemas de Gobierno Corporativo, que deben enfatizar el compromiso de los directivos con la creación de valor (como hacen, de una u otra forma, los tres códigos españoles de buen gobierno).

Otro tema importante es la visión social de la que también tenemos que impregnar a las finanzas. En palabras del Papa Benedicto XVI: "Es ciertamente útil, y en algunas circunstancias indispensable, promover iniciativas financieras en las que predomine la dimensión humanitaria. Sin embargo, esto no debe hacernos olvidar que todo el sistema financiero ha de tener como meta el sostenimiento de un verdadero desarrollo"15.

\section{CONCLUSIÓN.}

Estamos asistiendo a una crisis de grandes proporciones, que nos recuerda la famosa de 1929. En aquella ocasión se tomaron medidas en la economía en general y en las finanzas en particular. Ahora nos toca también hacer algo parecido,

${ }^{14}$ Puede verse el estudio de Edmans (2011) donde demuestra que hay una relación positiva entre la satisfacción de los trabajadores y la rentabilidad de los accionistas.

${ }^{15}$ Benedicto XVI (2009), Caritas in Veritate, $n^{\circ} 65$. En el $n^{\circ} 45$ de la misma encíclica se habla del microcrédito y de la microfinanciación. 
aunque en un contexto bastante diferente. Serían las reformas a las que nos hemos referido. Además hemos visto que la Teoría Financiera se ha dotado de un cuerpo científico que lleva a los profesionales a razonar y actuar de determinada manera, y que se ha desarrollado en un ambiente anglosajón, lo que la ha impregnado de una determinada cultura. Sin duda, esta crisis debe hacernos reflexionar sobre la orientación futura de la investigación financiera, así como deberemos matizar su enseñanza.

Pero nada de esto funcionará con garantías si no luchamos por mejorar los valores éticos. Esto no es fácil en una sociedad donde se aceptan con dificultad las normas morales, pero tenemos que hacer un esfuerzo para consensuar unos valores básicos y practicarlos.

En 2009 participé en una mesa redonda ${ }^{16}$ con un conocido economista español, José Antonio Herce, y otro conocido economista y exministro socialista, Jordi Sevilla. Hablando de estos temas Jordi Sevilla comentó: si cumpliéramos los diez mandamientos nos iría mucho mejor, el problema es que no los cumplimos. Coincido con esta idea, y por ahí tendremos que seguir trabajando.

Bastante luz en este campo puede darnos la Doctrina Social de la Iglesia, que siempre se ha mostrado crítica con los abusos económicos. Hace un tiempo llegó a mis manos un pequeño trabajo de Renau (2011) donde comenta la reacción indignada de Pío XI ante la crisis de 1929 o las palabras de ánimo de Benedicto XVI ante la crisis actual. El recientemente elegido Papa Francisco ha dado numerosas muestras de su preocupación por encontrar un mundo más justo ${ }^{17}$. Los valores que en este campo proclama la Iglesia Católica pueden ayudarnos en nuestro trabajo de encontrar un sistema económico y financiero mejor para los seres humanos.

\section{BIBLIOGRAFÍA.}

AMAT, O., Euforia y pánico, Profit, Barcelona, 2008.

BENEDICTO XVI, Caritas in Veritate, Palabra, Madrid, 2009.

BOLETÍN DE ESTUDIOS ECONÓMICOS, "Diferentes economías, diferentes problemas", Boletín de Estudios Económicos (núm. 204, 2011).

CAMPS, V., Breve historia de la ética, RBA, Barcelona, 2013.

CASSIDY, J., "Rational irrationality: interview with Eugene Fama", The New Yorker (13 de enero, 2010). Consultado por internet el 7 de enero de 2012: http://www.newyorker.com/online/blogs/johncassidy/2010/01/interviewwith-eugene-fama.html

\footnotetext{
${ }^{16}$ En un encuentro de consejos económicos y sociales españoles en Haro (La Rioja).

${ }_{17}$ Pueden verse, por ejemplo, sus intervenciones en la JMJ en Brasil (Francisco, 2013).
} 
EDMANS, A., "Does the stock market fully value intangibles? Employee satisfaction and equity prices", Journal of Financial Economics, (vol. 101, núm. 3, 2011), pp. 621-640.

FRANCISCO, Intervenciones del Papa Francisco en la JMJ en Brasil. Consultado por internet el 8 de septiembre de 2013: http://www.pastoralsantiago. org/2013/07/todos-los-discursos-del-papa-francisco.html

GALBRAITH, J.K., Breve historia de la euforia financiera, Ariel, Barcelona, 1991.

GÓMEZ-BEZARES, F., "Panorama de la teoría financiera", Boletín de Estudios Económicos (núm. 156, 1995), pp. 411-448.

GÓMEZ-BEZARES, F., "Una nota crítica sobre la actual investigación en finanzas", Cuadernos de Economía y Dirección de la Empresa (núm. 24, 2005), pp. $105-120$.

GÓMEZ-BEZARES, F., "Crisis y pecados capitales", El Economista (11 de mayo, 2009), p. 4.

GÓMEZ-BEZARES, F., "Presente y futuro de las finanzas. Situación y perspectivas de las finanzas a comienzos del siglo XXI", Contabilidad y Dirección (núm. 10, 2010), pp. 53-78.

JENSEN, M.C. y MECKLING, W.H., "Theory of the firm: managerial behavior, agency costs and ownership structure", Journal of Financial Economics (vol. 3, núm. 4, 1976), pp. 305-360.

MALKIEL, B.G. (1992), Un paseo aleatorio por Wall Street, Alianza Editorial, Madrid, 1992.

PÉREZ RAMÍREZ, J., Vidas paralelas. La banca y el riesgo a través de la historia, Marcial Pons, Madrid, 2011.

RENAU, J., "Humanizar la economía", Papeles Cristianisme i Justícia, suplemento del cuaderno 176, 2011.

REVUELTA, M.D., La Universidad Comercial de Deusto: 75 años formando profesionales para la empresa, Fundación Luis Bernola, Bilbao, 1992.

SÁNCHEZ MARIN, G. "La retribución del alto directivo en la empresa cotizada española: un análisis desde el gobierno corporativo", Boletín de Estudios Económicos (núm. 203, 2011), pp. 239-262. 